\title{
Portugal, Europa e o mundo: condição humana e geopolítica na filmografia de Manoel de Oliveira
}

Carolin Overhoff Ferreira

Universidade de São Paulo

\section{Introdução}

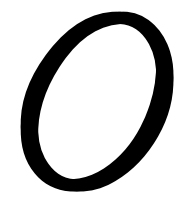

famoso poema Os Castelos, parte integrante de Mensagem (1934) de Fernando Pessoa termina com uma imagem da relação entre a Europa e o Novo Mundo, atribuindo a Portugal um papel de liderança. O país é destacado devido à sua capacidade de visão, sendo o seu olhar dirigido para um novo mundo, ou seja, para a América. Este protagonista geopolítico vindouro é nada mais do que a projeção visionária de Portugal:

A Europa jaz, posta nos cotovelos:

De Oriente a Ocidente jaz, fitando,

E toldam-se romanticos cabelos

Olhos gregos, lembrando.

O cotovelo esquerdo é recuado;

O direito é em angulo disposto.

Aquele diz Itália onde é pousado;

Este diz Inglaterra onde, afastado,

A mão sustenta, em que se apoia o rosto.

Fita, com olhar sphyngico e fatal,

O Ocidente, futuro do passado.

O rosto com que fita é Portugal. 
Esta imagem da vocação universalista de Portugal dialoga com representações anteriores na cultura portuguesa sobre o protagonismo lusitano na descoberta e na subseqüente interconexão com o mundo moderno, criadas pelos seus mais notórios visionários: Luís de Camões e Padre António Vieira. Argumentamos em outras ocasiões ${ }^{1}$ que Manoel de Oliveira apresenta em alguns dos seus filmes, nomeadamente aqueles que lidam com a expansão marítima - portuguesa ou europeia - uma perspectiva próxima a esses autores canônicos, incluindo Pessoa. Entretanto, o que diferencia a visão de Oliveira é a formulação da expectativa de liderança como condição, em que o mestre demonstra ser mais crítico em relação à "vã glória de mandar", de seu país no passado, e também consciente da sua marginalidade contemporânea em termos geopolíticos contemporâneos.

Chegamos à seguinte conclusão em relação à perspectiva oliveiriana sobre o papel de Portugal nos filmes Le Soulier de Satin (1985), Non ou a Vã Glória de Mandar (1990), Palavra e Utopia (2000), Um Filme Falado (2003), O Quinto Império: Ontem como Hoje (2004) e Cristóvão Colombo - O Enigma (2007), nos quais o realizador se debruça sobre o imperialismo e os descobrimentos portugueses:

Manoel de Oliveira é um cineasta da dúvida e das inquietações sobre a existência humana. O mundo nos seus filmes não é perfeito, o que reflete, como sugere Fausto Cruchinho (2003: 9), o seu profundo humanismo cristão: 'a sua tão conhecida perversidade não é senão um desejo insensato de melhor compreender o mundo tal qual Deus o criou'. No seu diálogo com os grandes mitos que tem vindo a fundamentar o imaginário português como povo eleito, ele procura desmascarar os motivos da sacralização

${ }^{1}$ Cf. FERREIRA, 2008; FERREIRA 2010. 
das tentativas de expansão imperialista e religiosa, portuguesa, europeia e norte-americana. Mas embora apresente às vezes uma visão próxima ao pós-colonialismo, esta nunca deixa de ser portuguesa e cristã. Por isso, as suas embarcações no imaginário nacional acabam sempre por serem descobrimentos do paradoxo: não só do paradoxo da existência humana, mas também da paradoxal, mas inquestionável missão e diferença do povo português. À procura da desmitificação, o cineasta mitifica novamente a identidade portuguesa, porque as descobertas das rotas marítimas não podem ser, na sua concepção, de outra origem senão divina. Como "cineasta de Cristo" não encontra outra solução do que reafirmar, na tradição de Camões e de António Vieira, senão a grandeza, pelo menos a singularidade de Portugal. ${ }^{2}$

Neste ensaio, gostaríamos de expandir a nossa interrogação sobre as implicações geopolíticas para o conjunto da obra de longas-metragens de Manoel de Oliveira, levando em consideração tanto o seu ponto de vista de que a cultura nacional possui algo importante a oferecer, porque preservou valores e tradições ocidentais, bem como a sua crítica à desumanização do mundo moderno, que se manifesta ora através da representação do autoritarismo da burguesia portuguesa tradicional, ora na análise da civilização ocidental - desde os seus primórdios, passando pela época dos descobrimentos até as hegemonias contemporâneas.

A oscilação do enfoque geográfico nos 25 filmes de curta e média-metragem e nos 28 de longa-metragem acompanha e altera o método universalista do realizador, ou seja, a sua tendência a buscar no particular conclusões generalizantes sobre os dilemas da condição humana. A condição humana no universo oliveiriano é fortemente enraizada na cultura judaico-

${ }^{2}$ FERREIRA, 2010, p. 145. 
cristã e debate-se sobretudo com a tensão entre a inclinação do ser humano para o pecado e a sua possível salvação através da espiritualidade.

Randal Johnson entende, por outro lado, que a postura de Oliveira é menos moral do que ética - derivando não só das suas reflexões sobre o mundo moderno, da sua formação religiosa, de uma noção da ética kantiana, mas também da sua reflexão sobre o cinema. $\mathrm{O}$ autor destaca como objetivo principal do realizador a instituição de uma relação participativa entre os filmes e os espectadores, abordada nas mais diversas escalas: "[os filmes] apresentam situações que envolvem o comportamento humano nas escalas individual, nacional e global, com o fim de provocar reflexões no espectador". ${ }^{3}$ Andrea Santurbano aponta na mesma direção quando explica o motivo que propulsiona a arte do realizador como uma "incansável busca gnosiológica sobre a natureza humana". ${ }^{4}$

Pretendemos neste ensaio entender melhor como o cineasta enquadrou o seu método universalista ao longo dos últimos oitenta anos perante as alterações geopolíticas sofridas por Portugal, a Europa e o mundo. Reconstruiremos a partir dos filmes do mestre as relações entre a sua preocupação com a condição humana e o impacto dos diferentes e cambiantes contextos nos quais tem filmado, desde 1931. As escalas compreendem o local - sobretudo através da região do Porto e do Douro -, o nacional - em relação à identidade do país -, o supranacional - devido à adesão de Portugal à Comunidade Europeia, em 1986 -, o transnacional - devido à história portuguesa e às explorações marítimas, bem como o global -

${ }^{3}$ JOHNSON, 2008, p. 91. Todas as traduções do inglês foram realizadas pela autora do texto.

${ }^{4}$ SANTURBANO, 2010, p. 215. 
como resultado dos efeitos da globalização que Portugal sofreu a partir dos anos noventa do século XX e da qual se orgulha de ter sido a vanguarda, como bem demonstra o poema de Pessoa acima citado.

\section{Local/Nacional}

O primeiro filme de Oliveira, o documentário Douro, Faina Fluvial (1931), parte de um interesse local, da cidade natal do realizador, sobretudo do seu porto. Esteticamente abraça as vertentes do cinema de vanguarda, ou seja, a montagem como forma de construir a realidade e de forjar a especificidade do cinema. Em uma época que Dudley Andrew cunhou - devido à dimensão internacional da linguagem cinematográfica como "fase cosmopolita", ${ }^{5}$ Douro segue o modelo das sinfonias urbanas, porém, através de uma abordagem invulgar, para não dizer oposta às "odes modernistas"6 cinematográficas anteriores, todas sobre grandes metrópoles europeias. Como diversos pesquisadores observam, na confrontação com estes retratos urbanos, sobretudo com Berlim - Sinfonia de uma Cidade (1927) de Walter Ruttmann, sobressai a centralidade do ser humano no filme do realizador portuense. Como bem lembra José Manuel da Costa, o filme "nunca toca a fronteira da 'arte abstracta' (e com ela a desumanização) que baliza o trabalho do realizador alemão". ${ }^{7}$ Apesar de Portugal ter estado à margem das profundas mudanças científico-tecnológicas no início do século vinte, comparado com os filmes sobre os grandes centros europeus, o jovem cineasta da periferia oferece uma visão mais universalista, ou seja, uma perspectiva interessada no conflito

\footnotetext{
${ }^{5}$ ANDREW, 2010, p. 62.

${ }^{6}$ MARTINS, 2010, p. 9.

${ }^{7}$ DA COSTA, 1999, p. 85.
} 
entre a tecnologia e o ser humano no mundo em viés de industrialização. O filme faz, de fato, frente à utopia da modernização ou a outros tipos de ideologia relacionados com ela.

O intuito de apontar uma problemática mais geral no contexto do local é também evidente no primeiro longametragem de ficção, Aniki-Bobó (1942), porém já se estende também para o nacional. $O$ filme, baseado em um conto de Rodrigo de Freitas, Meninos Milionários, debate a relação entre liberdade e repressão através de um grupo de crianças que mora no mesmo porto de Douro, focando violações éticas que resultam dos desejos humanos e que tornam necessária a reflexão sobre pecado e punição. $\mathrm{O}$ triângulo amoroso entre os dois meninos (Eduardinho e Carlitos) e Teresinha serve como pressuposto para questionar as transgressões realizadas em nome da paixão (o roubo de uma boneca por parte de Carlitos para agradar Teresinha e o acidente de Eduardinho devido à disputa entre ele e Carlitos); bem como para aliar a moral cristã - a redenção do roubo de Carlitos quando devolve a boneca a uma crítica do regime político - a ditadura de Oliveira Salazar por meio de personagens autoritárias, incluindo Eduardinho. ${ }^{8}$ O conflito universal entre os desejos e as restrições sociais apresenta-se, assim, entrelaçado com uma dimensão especificamente nacional. O filme mostra os diferentes degraus de contenção do comportamento humano e esta diferenciação revela o seu possível excesso: transgressão e redenção fazem parte da vida humana e são regulamentados através de um sentimento moral que se expressa, sobretudo, através da consciência (como a personagem Carlitos mostra em diversos momentos, sendo o seu pesadelo e a tentativa de fuga os

${ }^{8}$ Cf. JOHNSON, 2005, p. 48. 
exemplos mais emblemáticos), e, por isso, não se justificam medidas disciplinadoras extremas e repressivas (representadas pelo professor na escola e pelo policial).

No contexto da indústria cinematográfica criada nos moldes nacionalistas do regime ditatorial em 1931, a abordagem do dilema entre transgressão e punição, em conjunto com uma estética proto-neo-realista demonstra o quanto o filme de Oliveira se distingue dos filmes portugueses da mesma época. Embora seja um exemplo da "fase nacional" do cinema que se inicia com a criação do cinema sonoro em nível internacional, é a sua perspectiva universalista que se envolve de forma inusitada com o contexto da realidade nacional, retratado em um cenário local, que faz o filme transcender esta definição e anunciar precipitadamente a próxima fase: a "fase federada" ${ }^{10}$ na qual as tradições nacionais e a renovação da estética terão destaque.

Não surpreende que Oliveira se tenha precipitado estética e tematicamente em Aniki-Bobó, pois o regime repressivo apontado no filme impossibilitou já nesta altura o desenvolvimento do cinema nacional. O realizador foi uma das suas maiores vítimas, trabalhando primeiro, por exemplo, em Aniki-Bobó, em condições precárias e depois deixando quase de produzir. Apenas onze anos mais tarde surge um dos seus filmes mais polêmicos que, por expressar de uma forma inédita a relação entre o local e o universal, foi falsamente associado ao conservadorismo católico da ditadura. O Acto da Primavera (1963) debruça-se, como aponta Jacques Parsi, sobre o problema da representação do sagrado (e mais especificamente sobre a figura de Cristo) e encontra através da filmagem de um Auto do século dezesseis, o Auto da Paixão de Jesus Cristo, de Francisco

${ }^{9}$ ANDREWS, 2010, p. 65.

${ }^{10}$ ANDREWS, 2010, p. 69. 
Vaz de Guimarães, no interior profundo de Portugal uma solução para este desafio:

Em Acto da Primavera nunca é a Paixão que vemos, mas sim uma representação da Paixão. Tudo, o canto, o cenário, as pessoas, as barbas e os bigodes, toscamente postos ou usados (que não existem em Pasolini [O Evangelho segundo Mateus], e esta diferença é importante), o resvalar da representação no prólogo, tudo isto nos impede de qualquer identificação. Vemos a imagem de uma realidade: a de um Auto numa aldeia portuguesa que mostra a Paixão em Jerusalém e no Calvário. Por detrás dos postiços, dos cenários, da máscara, em suma, tal como por detrás da iconostase das igrejas ortodoxas, há algo mais, algo de inexplicável ou de transcendente. ${ }^{11}$

O inexplicável e o transcendente não surgem apenas da representação, mas estão relacionados com o motivo universal da Paixão, ou seja, com a promessa da redenção do ser humano. Nela consiste também a razão pela peculiaridade do final do filme que estabelece um vínculo estreito entre a Paixão e a realidade da aldeia. No epílogo, que segue ao sepultamento de Cristo, há outro momento de "distanciamento" representacional: uma montagem feita de imagens da atualidade de algumas das maiores guerras do século vinte, incluindo, por exemplo, a famosa imagem da nuvem em forma de cogumelo da bomba atômica, sobreposta ao rosto de Cristo. Esta "descida ao inferno", pela qual Cristo passou antes da ressurreição, relaciona através das imagens escolhidas o sofrimento das vítimas de guerra com aquele de Cristo. Sendo assim, a montagem não é apenas, como sugere Johnson, um "comentário dos ideais cristãos e do mundo moderno", ${ }^{12}$ mas, pelo contrário,

\footnotetext{
11 PARSI, 2001, p. 377-378.

12 JOHNSON, 2008, p. 93.
} 
a representação da possibilidade da presença/repetição do milagre da ressurreição e, com ela, da redenção do ser humano no meio dos pecados e da devastação do mundo contemporâneo.

Isto fica evidente em dois momentos. Primeiro, quando os aldeões, que lêem em um jornal uma notícia sobre a ameaça da bomba nuclear no final da montagem, são interrompidos por um deles que estava sendo barbeado. Ele anuncia, como se fosse novamente a representação do Auto Medieval, o retorno de Jesus. Aqui o processo da revelação da representação é invertido, porque dentro do distanciamento criado pela montagem surge a construção de uma cena que imita a realidade dos aldeões, e nesta irrompe agora a "peça" que, paradoxalmente, torna-se um anúncio percebido como sendo "verdadeiro" pelos presentes, por ser transferido da representação do Auto para a vida cotidiana, mesmo que representada, da vila trasmontana. $\mathrm{O}$ ficcional - claramente exposto - possui neste momento específico a qualidade do real (no sentido literário e psicanalítico). Segundo, porque a montagem encerra com a promessa simbólica da ressurreição, através da imagem primaveril de uma árvore em flor, indicando que o local remoto, onde os aldeões representam a cada ano o Auto que Oliveira filma como representação, ocupa, na verdade, um espaço entre a ficção e a realidade. Em outras palavras, estes aldeões são os verdadeiros representantes da Paixão, ou seja, a preservação do Auto Medieval possui um poder mágico: estamos em um local permeado pelo universal - onde a presença divina de Cristo e a promessa da redenção foram preservadas em seu estado mais puro.

Esta preservação da verdadeira - e universal - mensagem cristã nas pessoas simples, no povo do interior do país, encontra o seu oposto nas perversões da alta sociedade do país, esteja ela vivendo na capital ou no interior, tão nítida nos longas-metragens seguintes. Neles pode ser comprovado que 
a postura do realizador perante a figura e a Paixão de Cristo nunca se estende a uma afirmação da Igreja Católica e da sua doutrina. Pelo contrário, os filmes tratam de restrições supostamente morais de uma sociedade que perpetua, na verdade, convenções retrógradas como forma de dominação, impossibilitando assim relacionamentos amorosos sadios. $O$ Passado e o Presente (1972) inicia a "tetralogia dos amores frustrados" - da qual fazem parte Benilde ou a Virgem Mãe (1975), Amor de Perdição (1978) e Francisca (1981). Fausto Cruchinho acrescenta ainda Os Canibais (1988), devido à coerência temática, e explica que estes filmes colocam em cheque o peso da classe alta sobre as personagens jovens:

Estes cinco filmes, todos eles marcados pelo sinal da morte, constituem um tratado oliveiriano sobre as condições da vida amorosa em sociedade. (...) O que faz escândalo neste conjunto de cinco filmes de Oliveira, realizados durante o intervalo de quinze anos, é a obstinação dos seus personagens, femininos ou masculinos, em permanecerem virgens, contra toda a pressão social e cultural que os quer ver como reprodutores sexuais e, claro, reprodutores das relações de classe. $\mathrm{O}$ amor que Vanda vota aos maridos defuntos, o amor que Benilde vota a Deus, o amor que Teresa e Mariana votam a Simão, o amor que Fanny vota a José Augusto e, finalmente, o amor que Margarida vota ao Visconde só se manifesta porque está condenado ao fracasso. A simples possibilidade de esse amor, um amor ideal, platónico, se materializar, se consumar, é sistematicamente recusada por qualquer dos intérpretes amorosos. ${ }^{13}$

Autores canônicos da literatura nacional começam a ocupar um lugar preponderante na obra de Oliveira e servem de base para as explorações da sociedade portuguesa em nível

${ }^{13}$ CRUCHINHO, 2008, p. 55. 
local e nacional. A famosa "devoção sem limites" do realizador aos textos originais, que quase sempre são reproduzidos na íntegra, surge, como bem explica Fernando Cabral Martins, de um respeito que procura alcançar o ponto de vista do leitor dos livros: "E é o fato de abraçar esse ponto de vista que os tornam filmes de poesia, e não filmes que adaptem em sequências narrativas uma intriga anterior".${ }^{14}$ Os autores mais importantes que alimentam Oliveira a partir da Tetralogia são Camilo Castelo Branco (personagem em Francisca e autor de Amor de Perdição), José Régio (Benilde ou a Virgem Mãe) e Agustina BessaLuís (autora do romance Fanny Owen em que se baseia Francisca). O universo destes três escritores incontornáveis das letras portuguesas oferece a Oliveira subsídios para discutir a religiosidade etimológica, heterodoxa e barroca de Régio, ${ }^{15}$ a noção "do poder do ponto de vista e da parcialidade de toda representação", ${ }^{16}$ compartilhada com Bessa-Luís, já problematizada na obra de Castelo Branco, da qual Oliveira desvenda em Amor de Perdição a veracidade, normalidade e repetitividade do sofrimento por causa do amor, "para desestabilizar a forma como, usualmente, esse livro é interpretado, o modo reducionista como o romance ficou guardado no imaginário cultural luso-brasileiro" (OLIVEIRA, 2010, p. 51). A resistência à canonização da obra de Camilo Castelo Branco e da sua pessoa será revisitada no ensaio fílmico O Dia do Desespero (1992).

O efeito negativo da sociedade sobre os indivíduos já esteve presente em Aniki-Bobó; mas nos filmes da Tetralogia paira de forma mais aguda uma sensação de opressão da qual

\footnotetext{
${ }^{14}$ MARTINS, 2010, p. 11.

${ }^{15}$ Cf. CORRADIN; SILVEIRA, 2010, p. 21.

${ }^{16}$ CARDOSO, 2010, p. 222.
} 
as personagens procuram escapar através da perversão dos próprios sentimentos que as leva quase sempre à morte (em Benilde, Amor de Perdição e Francisca). Nestes filmes as fortes raízes autoritárias da sociedade portuguesa estão em primeiro plano, responsáveis pela produção de gerações de jovens dispostos a se auto-sacrificarem, desde o Romantismo, nos anos 40 e nos anos 70 do século vinte. A sociedade e a contaminação do seu código moral surgem como culpados, sendo que em $O$ Passado e o Presente e Benilde o envolvimento da Igreja Católica nesta perversão é mais perceptível.

Esteticamente, a Tetralogia enquadra-se no Novo Cinema português e, assim, no cinema "federado" mundial, caracterizado por uma linguagem cinematográfica que se espalha através de ondas pelo mundo. O intuito de Oliveira é evidenciar a representação para desvendar a construção da realidade, seja através da revelação do aparelho cinematográfico ou, como Pedro Guimarães argumenta, através da direção de atores. Apesar do impacto internacional, este "cinema federado" incide em uma luta nacional, ${ }^{17}$ pois defende não só um cinema revigorado, mas também uma renovação dos códigos sociais. Os filmes da Tetralogia podem ser considerados excelentes exemplos para demonstrar esta luta nacional no caso do cinema português.

\section{Supranacional/Transnacional}

Quando Portugal ingressa na Comunidade Européia, a alteração da condição geopolítica se manifesta através do alargamento dos horizontes de Manoel de Oliveira. A partir de Le Soulier de Satin / O Sapato de Cetim (1985) o realizador vai além

${ }^{17}$ Cf. ANDREWS, 2010, p. 75. 
do local e do nacional, iniciando um debate sobre o supranacional e o transnacional. Como co-produção além fronteiras, luso-germano-francesa, o filme é um reflexo da nova situação, pois enfoca a história imperialista da Europa nos dois primeiros séculos das expansões marítimas, como alegoria dos tempos atuais. A primeira contemplação do novo contexto aponta a marginalidade de Portugal, porém, já assinala que esta posição na corrida para uma divisão do mundo pela Europa surge do seu duplo papel como agente e vítima das políticas de expansão. Como resultado, a relação entre a condição humana e o nacional é levada para outro nível. Baseado no texto do francês católico Paul Claudel, as implicações da utilização de um texto original não português são complexas: a impossibilidade de um amor terrestre é novamente presente, mas surge como analogia dos desejos mundanos de poder, que substituem o lugar do microcosmo da sociedade portuguesa e das suas perversões. Além disso, a renúncia ao amor é aqui escolha consciente da personagem feminina (doña Prouhèze: Patricia Barzyk), reconhecida pelo protagonista (don Rodrigue: Luís Miguel Cintra) no final da sua vida quando esse é forçado a reavaliar o seu desejo de exercer poder no Novo Mundo, que foi nada mais do que uma reação à rejeição amorosa.

O Sapato de Cetim não só censura as ambições do poder mundano, patentes nas grandes nações européias, mas questiona, de forma geral, o imperialismo impulsionado pelo descobrimento das Américas e pelas conquistas no Norte da África. Para ultrapassar o paradoxo da condição humana - a vocação para a dominação e a procura da espiritualidade - são indicados dois caminhos: Rodrigue, Vice Rei Espanhol nas Américas, e Dona Prouhèze, a esposa do conselheiro do Rei, serão recompensados fora da história pela sua abdicação ao amor físico, enquanto Marie des Sept-Épées (Anne Consigny), a filha de Prouhèze que esta entrega a Rodrigue, se une ao rei 
da Áustria em um projeto religioso para combater os turcos muçulmanos, unindo assim o amor ao serviço a Deus. No contexto da incapacidade de uma união política na Europa (neste caso contra a invasão turca) devido à prevalência de interesses nacionais, a renúncia do poder por parte de Rodrigue aproxima-o à situação involuntária de Portugal. Mas o fato de que Portugal não tenha desempenhado um papel político nessa altura (lembrado através de duas curtas cenas que Oliveira acrescenta à peça claudeliana), o torna agora, ao contrário dos filmes da tetralogia que se baseiam no autoritarismo local, em um possível representante de uma alternativa política no contexto supranacional. Esta alternativa deve-se à situação geopolítica periférica e aproxima Oliveira, paradoxalmente, pela primeira vez da perspectiva de Pessoa no poema acima citado. A visão crítica e invulgar sobre o colonialismo europeu, consiste, além das inovações estéticas o grande mérito do filme - no surgimento de um realizador à margem dos grandes centros europeus, mas que agora filma a sua visão na França, e alcança com ele atenção internacional. $\mathrm{O}$ mestre coloca Portugal no mapa do "cinema mundial", aquele cinema que, segundo Andrews, "dá expressão a culturas silenciadas" ${ }^{18}$ pois a partir dos anos oitenta o cinema português começa a se fazer ouvir mais fortemente em todo o mundo.

\section{Global}

Inflexões nacionais, mesmo que sutis, são uma das principais características do cinema mundial. O amor ao país é, contudo, apenas passageiro nos quinze anos seguintes, nos quais o realizador começa a produzir um filme por ano, quase

${ }^{18}$ ANDREWS, 2010, p. 79. 
sempre com apoios de agências financiadoras de cinema ou de canais televisivos europeus, sobretudo da França. Uma perspectiva similar volta apenas em Non ou a Vã Glória de Mandar, que se alia à crítica feroz ao imperialismo português, e em Viagem Ao Princípio do Mundo (1997) relacionado à tensão entre a memória individual e a coletiva. A sugestão ou discussão de elementos positivos na cultura portuguesa será retomada e se tornará quase constante, como observamos no início deste ensaio, apenas na primeira década do século vinte, nos filmes Palavra e Utopia, Um Filme Falado, O Quinto Império Ontem como Hoje e Cristóvão Colombo - O Enigma. Palavra e Utopia resulta das comemorações do "Descobrimento" do Brasil e é a primeira produção do mestre que acompanha a alteração do mapa cinematográfico mundial, ou seja, com um orçamento elevado, financiado não só por países europeus (Portugal, Espanha, França), mas também pelo Brasil, apresenta noções associadas ao "cinema global", no qual "a distinção aparece menos através do estilo cinematográfico, do que pelas alterações nos mecanismos de produção e distribuição" ${ }^{\prime 19}$ De fato, o filme autoral faz parte de um grupo crescente de produções de grande orçamento, impulsionados por um protocolo de produção cinematográfica com o Brasil. Mas devido ao seu tema, Palavra e Utopia foca o seu discurso na transnacionalidade portuguesa, iniciado em Non ou a Vã Glória de Mandar, isto é, na revisão do colonialismo na África e no Brasil, enquanto os filmes seguintes possuem um ímpeto geopolítico mais abrangente, de escala global, pois discutem a divisão do mundo ocidental e oriental como resultado do ataque terrorista ao World Trade Center, no dia 11 de Setembro de 2001.

${ }^{19}$ ANDREWS, 2010, p. 80. 
Embora cada filme apresente perspectivas diferentes, $\mathrm{O}$ discurso continua a ser parecido com aquele que encontramos em O Acto da Primavera e, de forma mais sutil, em O Sapato de Cetim. Contudo, está agora contextualizado na nova ordem global: Portugal poderia servir de modelo em termos de valores, sendo que a sua identidade anti-moderna no mundo industrializado (resistente a abraçar a modernização tecnológica que não leve a condição humana em consideração) coincide com a sua identidade transnacional histórica (na sua idealização camoniana e vieirense como agente positivo da globalização), responsável pela aproximação dos povos. Colocado de outra forma, Manoel de Oliveira inverte nestes filmes do século vinte e um o seu método: em vez de tirar conclusões gerais (sobre a condição humana) do contexto particular (do autoritarismo ou da preservação de valores em Portugal), quando discute a geopolítica global contemporânea e o lugar de Portugal dentro desta, ele tira conclusões particulares - a possível importância de Portugal - do contexto geral (da crítica à hegemonia dos países ricos europeus e dos Estados Unidos). Paradoxalmente, nos filmes onde a perspectiva geopolítica se alarga para o supranacional, $\mathrm{o}$ transnacional e o global, a perspectiva do realizador sobre aquilo que ele considera como sendo universal muda: da condição humana no mundo moderno para o legado do povo português, ou seja, para uma visão próxima do poema pessoano supracitado que defende a vocação universalista de Portugal.

\section{Universal/Local}

Antes destas interrogações supranacionais, transnacionais e globais associadas a críticas ao nacional e, assim, inclinadas para posições afirmativas acerca dos valores patrícios de maior 
ou menor grau, os filmes de meados dos anos oitenta até o final do século vinte são dominados por temáticas que seguem a interrogação da condição humana sem maiores implicações geopolíticas, desdobrando-se majoritariamente sobre perguntas de ordem ética e religiosa (Mon Cas /O Meu Caso, 1986; Divina Comédia, 1991; O Convento, 1995; Inquietude, 1998; Je Rentre à la Maison/Vou para Casa, 2001), social (ACaixa, 1994), ao mesmo tempo que o paradigma do amor como lugar predileto da manifestação das contradições sociais e humanas se manifestava novamente no contexto local (Os Canibais; O Dia do Desespero, 1992; O Convento, Inquietude, Vale Abraão, 1993; Party, 1996), que pode estender-se até o contexto europeu ( $A$ Carta, 1999; Vou para Casa).

O Meu Caso, uma co-produção luso-francesa, desenvolve ainda mais a problemática da espiritualidade presente no filme anterior, O Sapato de Cetim, afastando-se, no entanto, do contexto supranacional em termos de produção, para abordar a condição humana da forma mais universal possível. Esteticamente representa outro ponto de viragem: se a exposição do aparelho cinematográfico e da ficcionalidade da representação eram alcançadas desde $O$ Acto da Primavera, sem abrir mão dos textos originais em sua íntegra, O Meu Caso é um diálogo, ou, como expõem Flávia Maria Corradin e Francisco Maciel Silveira "uma releitura cinematográfica" ${ }^{20}$ da peça homônima de José Régio. Nesta peça, um homem, o Desconhecido (Luís Miguel Cintra), aparece pouco antes do início de uma peça de boulevard no palco, para contar ao público "o seu caso". Embora argumente que esteja lá por inspiração divina, o invasor nunca chega a narrá-lo, pois é continuamente interrompido por outras personagens que se acham igualmente importantes: a atriz

${ }^{20}$ CORRADIN; SILVEIRA, 2010, p. 14. 
principal, o porteiro, o autor e outro espectador. Oliveira filma a farsa de dimensão alegórica três vezes: uma vez utilizando o texto de Régio na íntegra; uma segunda vez como se fosse um filme mudo, com os típicos gestos largos, mas com uma voz em off, que lê o texto Foirade II, de Samuel Beckett, e, finalmente, outra vez a peça de Régio, porém, com a rotação do som invertida. Lembrando o final de $O$ Acto da Primavera, as três repetições terminam com uma montagem de "filmes documentários e jornais televisivos que expõem crimes cometidos pelo homem contra si mesmo e contra a natureza: guerras, motins, fuzilamentos, desastres ecológicos, fome, genocídio" (CORRADIN; SILVEIRA, 2010, p. 16). A esta montagem segue-se a encenação do Livro de Jó, cujo final feliz - o perdão por Deus - é ironicamente comentado, pois a cenografia do desfecho, onde Jó (Luís Miguel Cintra) e a sua mulher (Bulle Ogier) se encontram, remonta à Cidade Ideal, reconstrução do famoso quadro de Piero della Francesca. Corradin e Silveira resumem a investigação da condição humana no filme, mediada pela exposição dos aparelhos que a registram:

O tema comum aos três paradigmas com que dialoga a película oliveiriana parece residir na incompreensão e na incomunicabilidade que desterram o ser humano para uma solidão existencial (...). Não estranha, pois, que uma das repetições registre a peça de Régio (...) numa sequência de filme mudo. Nós, na posição de espectadores do drama alheio, postos na distância de uma contemplação mediada pela frieza de olhos eletrônicos, somos, ao cabo, surdos ou impossibilitados de ouvir as queixas do outro, para as quais não damos a mínima atenção. ${ }^{21}$

${ }^{21}$ CORRADIN; SILVEIRA, 2010, p. 18-19. 
Ao deixar para trás as dimensões geopolíticas das mais variadas ordens, esta abordagem da condição humana contempla a adesão a uma comunidade maior, pois os problemas identitários encontram-se ancorados na cultura judaico-cristã como um todo. Apesar de lidar com a mesma questão como em O Acto da Primavera, duas décadas mais tarde O Meu Caso vai, pela primeira vez, além de fronteiras físicas para falar do metafísico. Outra diferença pode ser encontrada no desfecho irônico, referido acima. Apesar de Jó renascer como homem novo no final, sendo homem este renascimento é visto com cautela e com a distância habitual no cinema oliveiriano.

Esta ironia em relação à condição humana une o filme ao Sapato de Cetim e também a Os Canibais que o segue: a redenção não significa que Jó se torne uma pessoa melhor, ela simplesmente indica a existência do divino. Enquanto Jó recupera em $\mathrm{OMeu}$ Caso a sua ligação com este, Os Canibais, que retorna à sociedade portuguesa burguesa do século dezenove, foca na predisposição do ser humano de se afastar de Deus para viver de forma amoral e hedonista. Na cena final, em que a sociedade se transforma em porcos e lobos, é estabelecida novamente uma relação com um texto do Velho Testamento, com a dança ao redor do Bezerro de Ouro. Nesta dança contemporânea os homens "perderam a sua verdadeira humanidade e se tornaram animais", ${ }^{22}$ como nota Peter Buchka.

Oliveira realiza apenas mais um filme no qual ele suprime fronteiras geográficas para debater a condição humana nos moldes do Cristianismo: A Divina Comédia (1991), filmado logo após o grande painel histórico de Non ou a Vã Glória de Mandar. Mas onde $\mathrm{O} \mathrm{Meu}$ Caso foca o homem moderno e o problema da incomunicabilidade (ninguém quer ouvir os "casos" do outro) e da provação (devido ao poder, à justiça, à sabedoria e ao amor

${ }^{22}$ Apud MAIER-SCHOEN, 2004, p. 46. 
de Deus, incompreensíveis para o homem), A Divina Comédia retoma a temática de Aniki-Bobó: "o lábil equilíbrio que separa o pecaminoso do natural na esfera religiosa. A primeira grande questão afrontada, então, diz respeito ao moralismo católico que faz as contas com o irresoluto a não ser por via insatisfatoriamente dogmática -, dilema entre a razão e o instinto, o espírito e a carne ${ }^{\prime \prime}{ }^{23}$ como comenta Andrea Santurbano. A relação intrínseca entre o bem e o mal, o pecado e a santidade é explorada em um manicômio, onde se encontram internadas pessoas que se confundem com personagens ilustres da literatura ocidental: 0 Anticristo de Friedrich Nietzsche, o Profeta de José Régio, Sonia e Rascolnikov de Crime e Castigo e Ivan e Aliosche Karamazov de Os Irmãos Karamazov, ambos romances de Fiódor Dostoiévski; além de personagens bíblicos, do Antigo e do Novo Testamento: Adão e Eva, Jesus, Lázaro, Maria, Marta e o Fariseu. A intertextualidade vai mais longe do que em $\mathrm{O} \mathrm{Meu} \mathrm{Caso,} \mathrm{o} \mathrm{que}$ leva Santurbano a afirmar que "a evolução do cinema oliveiriano, vinte anos depois do regresso à ficção e às adaptações literárias, encontra aqui a sua revolução".${ }^{24}$ Além da revolução estética, é um dos filmes do mestre mais complexos e desafiadores sobre a condição humana:

Sempre misturando tragédia e ironia, essa arte é um convite a desmascarar a ilusão de liberdade que preside aos atos do homem, para que ele se possa tornar livre, sobretudo, de si mesmo, sabendo enfrentar todas as consequências. Afinal de contas, reafirmando o postulado de Oliveira, inferno, purgatório e paraíso pertencem a esta terra: o bem e o mal são consubstanciais ao homem. E nisso há a lição de José Régio. ${ }^{25}$

${ }^{23}$ SANTURBANO, 2010, p. 3.

${ }^{24}$ SANTURBANO, 2010, p. 211.

${ }^{25}$ SANTURBANO, 2010, p. 215-216. 
Esta lição é desenvolvida ao longo da década de noventa através do paradigma do amor. Focalizando novamente a paixão e os seus meandros, o realizador retorna à sociedade portuguesa e às dificuldades de aí encontrar relacionamentos saudáveis. Mas, as razões apontadas não dizem mais respeito ao autoritarismo arcaico, e sim à divisão dos gêneros. A vida do autor predileto, Camilo Castelo Branco, oferece mais uma vez um testemunho das batalhas amorosas em O Dia do Desespero, bem como uma abordagem inédita da problemática da representação (analisada em pormenor por Pedro Guimarães) e da musealização de um grande autor. A partir de 1993, o protagonismo passa para as mulheres. A figura mais emblemática de toda a obra de Oliveira é a mítica Ema (Leonor Silveira) do Vale do Douro, que rompe com todas as convenções, querendo desafiar os papéis sociais atribuídos a homens e mulheres, mas acaba por tornar-se vítima da tentativa de abolir a oposição binária entre os gêneros. Interrompido por uma fábula sobre os desejos elementares das classes sociais mais baixas em A Caixa, a separação dos gêneros volta em O Convento e em Party.

Como nos dois filmes anteriores, $O$ Convento é situado em um espaço local com dimensão mística (o convento da Arrábida) e questiona outra vez os binarismos do Catolicismo através de personagens que remontam à união dos seres separados, o mito grego do andrógino que já aparecera em A Divina Comédia e Vale Abraão. Desta vez está patente nas personagens Hélène (Catherine Deneuve) e Piedade (Leonor Silveira) que se apresentam como "duas metades de um todo que não se sustenta, daí o espectador não se sentir seguro para identificar nelas as agentes do bem ou do mal".${ }^{26} \mathrm{O}$ filme, que se baseia em

${ }^{26}$ CARDOSO, 2010, p. 232. 
uma idéia de Agustina Bessa-Luís, é afirmativo no seu desfecho sobre a possibilidade desta união através da reunião do casal protagonista que deixa para trás tentações de todo tipo mefistofélicas e bíblicas. A inclinação da cultura portuguesa para o universal aparece sutilmente na razão pela qual o casal - o investigador americano Michael Padovic (John Malkovich) e a sua esposa francesa Hélène - encontra-se em Portugal: o pesquisador procura demonstrar que William Shakespeare era, na verdade, um português de descendência judaica.

Em Party, Oliveira volta a explorar a suposta oposição dos gêneros através das restrições que as mulheres sofrem na sociedade, sobretudo na instituição do casamento, afirmando o desejo feminino de sensualidade, contrariado pelos homens. Inquietude, de 1998 e A Carta, de 1999 seguem o mesmo caminho, focalizando, contudo, sempre novos aspectos do papel da mulher ou do seu relacionamento com o sexo masculino. Em Inquietude é a imortalidade que Oliveira interpreta como sendo desejada pelo homem (como também em Vou para Casa), mas característica da mulher, enquanto em $A$ Carta são destacados os valores que uma mulher é capaz de colocar acima do seu desejo. Nestes cinco filmes (poder-se-ia incluir também $A$ Divina Comédia) existe uma visão da mulher como signo do mistério, considerada, em última análise, ela própria, uma mitificação. Fausto Cruchinho a expõe da seguinte forma:

Manoel de Oliveira soube construir, desde o seu primeiro filme e através da sua obra de ficção ou de documentário, um duplo dispositivo: o ver e o ser visto. (...) Esse mecanismo permite filmar em particular a mulher que, em Oliveira, se expõe como numa mostra, à vista de todos e também do cineasta. Essa exposição permite um julgamento moral e estético, como se a mulher fosse um objecto cuja beleza e cuja moral fossem, simultaneamente, produto da invenção do homem e sujeito incompreensível, talvez por não ser 
humano. A mulher surge, assim, como objecto de fruição erótica e sujeito de uma interrogação ontológica. Porém, à semelhança dos cineastas anteriormente citados [Buñuel, Hitchcock], também eles tocados pela religião católica como Oliveira, a mulher é o princípio do mundo e origem do homem. ${ }^{27}$

A caracterização da personagem feminina em $A$ Viagem ao Princípio do Mundo não foge à regra, embora o filme discuta a migração sobre o prisma da memória. Assim, Oliveira fecha a década retornandoà temática nacional de Non..., mas na contramão, pois não lhe interessa falar da expansão, mas sim de um emigrante (um ator francês, cujo desejo de conhecer a vila do pai desencadeia a viagem do filme). Em vez de questionar a identidade portuguesa para afirmá-la no final, o filme oferece dois modelos para lembrar a história: um individual e um coletivo. Mauro Rovai compara estas duas formas de memória, das quais uma é representada pelas lembranças do realizador (um alter ego do próprio Oliveira) que se depara, sobretudo, com a destruição, e a outra se baseia na forma como os habitantes do Portugal profundo lidam com o passado. O autor chega à seguinte conclusão sobre a razão da comparação no filme:

Isso não sugere necessariamente uma forma mais humana ou mais justa de lidar com o passado, todavia, nos coloca diante de uma maneira diferente de percebê-lo. Em vez de lugares arruinados, uma pequena aldeia que possui algumas práticas sociais (portar-se à mesa, armazenar mantimentos, o que vestir, como guardar o luto etc.) que oferecem uma maneira distinta de lidar com a passagem do tempo. ${ }^{28}$

${ }^{27}$ CRUCHINHO, 2008, p. 49-50.

${ }^{28}$ ROVAI, 2008, p. 133. 
De fato, esta forma distinta de lidar com o tempo não é apresentada como alternativa pelo seu anacronismo. Mas ela possui uma dignidade oposta às ameaças da modernidade que são interpretadas como geradoras de destruição, desumanização e guerra. Enquanto os filmes sobre o paradigma do amor são paradoxais, pois questionam o binarismo associado ao Catolicismo, ao mesmo tempo em que mitificam muitas vezes, como este, a mulher, Viagem ao Princípio do Mundo, ao incluir referências e evocações da situação europeia ou da política internacional, ${ }^{29}$ apresenta contradições parecidas àquelas apontadas nos seis filmes sobre a expansão marítima.

A visão sobre a classe alta, por outro lado, mantém-se crítica, estendendo-se da década de noventa (Inquietude e $A$ Carta) para os filmes do novo milênio, isto é, para O Princípio da Incerteza (2002), O Espelho Mágico (2005), Belle Toujours/Sempre Bella (2006) e Singularidades de uma Rapariga Loira (2009), tanto no contexto local quanto europeu (francês). Neste mundo da alta burguesia a vida é claustrofóbica devido às convenções hipócritas, emprestadas pela religião católica. Intercalado aos filmes que procuram posicionar Portugal perante a nova ordem global, Manoel de Oliveira realiza esses filmes auto-referenciais, focando cada vez mais nas mulheres, no desmascaramento da condição feminina que se debate entre o bem e o mal, a santidade e o pecado.

Nos tempos atuais, em O Princípio da Incerteza, baseado em um romance de Agustina Bessa-Luís, a jovem Camila (Leonor Baldaque) é ainda obrigada a casar-se por interesse, enquanto a devassa Vanessa (Leonor Silveira) possui o direito (masculino) de manipular e de escolher o parceiro. As mesmas atrizes invertem a sua posição na sociedade em $O$ Espelho Mágico, novamente com base em um livro de Bessa-Luís, no qual

${ }^{29}$ Cf. ROVAI, 2008, p. 122. 
Alfreda (Leonor Silveira) é uma aristocrata estéril e obcecada pelo desejo de ver a Virgem Maria, e Vicenta, uma manipuladora que faz o papel da Virgem em troca de dinheiro. O que está em pauta é a fluidez das definições atribuídas às mulheres, como explica Paola Poma:

Como uma espécie de holografia, as várias faces das duas mulheres se interpõem e se recompõem numa outra ordem, não mais a da fixidez, qualidade intrínseca do cinema, mas tangenciando a ficção, a memória e a realidade simultaneamente. Todas as mulheres estão lá, arquetípicas, com o princípio da incerteza movendo os seus desejos. ${ }^{30}$

A questão que se coloca é onde está uma mulher real que não sirva como exemplo de uma condição feminina abstrata e talvez demasiadamente vinculada à visão cristã do mestre português.

A divisão cada vez maior entre o refinamento estético do cinema de Oliveira e as perspectivas paradoxais - seja por destacar os valores portugueses como resolução para a situação do mundo contemporâneo, seja por debater as idéias bíblicas relacionadas com o papel das mulheres - pode ser observada nos últimos dois filmes: Cristóvão Colombo - O Enigma e Singularidades de uma Rapariga Loira. Apesar de desvendar a dimensão ambivalente da suposição de que Colombo era português, o filme sobre o navegador genovês afirma a vocação universalista do povo português, através da sua disposição de navegar mares desconhecidos, como nenhum outro filme antes (sobretudo na cena do casamento do casal da Silva com o mar). ${ }^{31}$ O último filme do mestre, Singularidades de uma Rapariga Loira, por sua vez, demonstra como o personagem principal Macário

${ }^{30}$ POMA, 2010, p. 241.

${ }^{31}$ Cf. FERREIRA, 2010, p. 143. 
(Ricardo Trêpa) deixa-se levar pelas aparências (mais uma abordagem do problema da representação do verdadeiro) e apaixona-se por uma menina bela, mas cleptomaníaca (Catarina Wallenstein). Ou seja, o filme apresenta pela primeira vez uma mulher cujo mistério se revela vazio, reduzindo-a a uma simples ameaça para os homens.

\section{Conclusão}

O conjunto da obra de Manoel de Oliveira estende-se por oitenta décadas. Seria ambicioso demais tentar tirar conclusões mais profundas sobre a relação entre a condição humana e as dimensões geopolíticas nas quais se desenvolveu e que são também tema dos seus filmes. Gostaria de tentar, contudo, apontar as linhas de força que se revelaram neste ensaio.

No início da carreira, em 1931, o realizador usa em Douro, Faina Fluvial o local como plataforma para falar de questões mais universais, pois dizem respeito à condição humana no mundo moderno que está se industrializando. Depois, o método universalista contempla a realidade nacional, cuja tendência para a repressão é revelada pela primeira vez através do local, em Aniki-Bobó, o primeiro longa-metragem, de 1942. Este método surge com força apenas em outro documentário, OActo da Primavera, de 1963. A transgressão e o problema de se redimir do pecado persiste, contudo, na denúncia das perversões da anacrônica classe alta portuguesa, na "Tetralogia dos amores frustrados", que é filmada de 1972 a 1981.

A questão do poder, representado por essa elite em nível local, ganha um novo enquadramento quando a situação política não só se altera, mas alcança uma nova escala: o supranacional em O Sapato de Cetim, um ano antes da adesão de Portugal à Comunidade Europeia, em 1986. [O modo de produção transnacional oferece a nata dos estados europeus e sua história imperialista como alvo, embora seja mantido o 
amor como ponto mais fraco do homem, visto agora como troféu na luta entre o mundano e o espiritual.

Após alcançar esta dimensão supranacional e podendo contar com o apoio financeiro desta realidade geopolítica, Oliveira avança para a próxima escala, até então só presente nos seus documentários: O Meu Caso, de 1986, apresenta novamente o homem moderno como personagem principal que se espelha no Jó bíblico, ou seja, constrói um personagem universal que serve de referência para toda a cultura ocidental contemporânea. Mesmo que esteja situado em Portugal, isto também ocorre com Os Canibais, cujo personagem principal aponta para a validade da parábola para os tempos modernos.

Non ou a Vã Glória de Mandar, de 1990, muda o registro, pois aborda o envolvimento de Portugal no imperialismo europeu, mas inclui, por outro lado, o aviso de que Portugal possui no fundo uma vocação universalista que distingue o país das outras nações e que consiste na "dádiva" dos descobrimentos que foram transnacionais no seu ímpeto. A fase que se debate com as possibilidades e restrições da escala supranacional encerra com A Divina Comédia, que aborda da forma mais complexa e intertextual possível a negociação do ser humano com o pecado. A escala é a mesma de $O$ Sapato de Cetim e de $\mathrm{O}$ Meu Caso: a cultura ocidental, mas libertada das suas implicações políticas, o que faz com que o realizador atinja, com este filme, o auge do seu método universalista.

Com Portugal no mapa mundial e com um cinema de visão própria, associado, sobretudo, ao mestre Oliveira, o realizador entra no ano da produção desse filme, 1991, na sua fase mais prolífica. A partir daí explora de diferentes ângulos os seus temas, acrescentando talvez um: a condição feminina e a sua relação com a polarização cristã entre o bem e o mal, a santidade e o pecado. Como nos primeiros filmes, o mestre volta para a escala local para contextualizar a mulher e os seus desejos, em que Portugal ainda serve como pano de fundo 
conservador e, dependendo da época escolhida, repressor. Algumas vezes, Oliveira cruza as fronteiras, quando o modo de produção o permite, diversas vezes para a França, e uma vez para o Brasil. Neste último caso volta a apontar a vocação universalista da sua nação, atribuindo a Portugal o potencial de desempenhar um papel principal na nova ordem global.

O último ponto de viragem no que diz respeito à relação entre a condição humana e a dimensão geopolítica se anuncia durante a crise na Yugoslávia em Viagem ao Princípio do Mundo, de 1997, onde os problemas políticos são apenas mencionados em segundo plano. Só após o atentado terrorista em 11 de Setembro de 2001, quando se faz notar de forma mais contundente, o global toma fôlego na obra do mestre, mesmo que não seja como única preocupação, pois ele mantém o seu interesse na pesquisa da condição feminina. Nos filmes de viés geopolítico, o local ou o nacional servem como ponto de partida para criticar a hegemonia das nações poderosas - da Europa e dos Estados Unidos -, bem como para assinalar as verdadeiras virtudes cristãs, cuja preservação em Portugal o mestre defende desde $O$ Acto da Primavera.

Seguindo o seu desejo de investigar a condição humana através dos conceitos chaves da ética cristã - o pecado e a redenção -, e desenvolvendo uma estética que questiona a capacidade do cinema de representar qualquer verdade, Manoel de Oliveira incorporou os problemas nacionais - o autoritarismo antes e depois da ditadura salazarista -, o supranacional - depois da adesão econômica à Comunidade Europeia através da postura crítica perante o seu imperialismo -, o transnacional - a vã glória de mandar do império português, mas também a importância dos seus descobrimentos -, deu visibilidade ao cinema português no contexto mundial, e ainda comentou a globalização e a nova ordem que dela resultou. Nestas mais diversas e interconectadas escalas, os filmes mais 
extraordinários do realizador são, na minha opinião, aqueles em que ele segue sem preocupações geopolíticas o seu método universalista que surge da tentativa de equacionar o pecado e a redenção do homem no mundo moderno, seja através do local ou de forma mais abstrata. Os filmes que comentam mais diretamente a situação geopolítica de Portugal, da Europa e do mundo acabam por serem involuntariamente paradoxais (isto vale também para aqueles que procuram quebrar as oposições binárias estabelecidas na Bíblia em relação à condição feminina), pois defendem as virtudes da nação marítima e substituem o interesse na condição humana pelo elogio pessoano (e não só) da vocação universalista de Portugal. Arrisco-me a dizer que a força do cinema de Oliveira reside na exploração das tensões entre a condição masculina e o mundo moderno ou entre ele e a sua herança judaico-cristã, ou seja, quando dizem respeito ao dilema do próprio mestre.

\section{Bibliografia}

ANDREW, Dudley. Time zones and jetlag - the flows and phases of world cinema. In: DUROVICOVA, Natasa; NEWMAN, Kathleen (Org.). World Cinemas, Transnational Perspectives. Routledge, Londres e Nova Yorque, 2010. p. 59-89.

DE BAECQUE, Antoine; PARSI, Jacques. Conversas com Manoel de Oliveira. Porto: Campo das Letras, 1999.

CORRADIN, Flávia Maria; SILVEIRA, Francisco Maciel. O Meu Caso Rebobinado. In: JUNQUEIRA, Renata (Org.). Manoel de Oliveira: Uma Presença - Estudos de Literatura e Cinema. São Paulo: Perspectiva, 2010. p. 13-28.

COSTA, José Manuel da. Douro, Faina Fluvial de Manoel de Oliveira (1931). In: GOULET, Pierre Marie; COSTA, José Manuel; GARCIA, Teresa; DIAS, Miguel (Org.). O Olhar de Ulisses, Vol. 1. Porto: Sociedade Porto 2001 \& Cinemateca Portuguesa, 1999. p. 82-87. 
CRUCHINHO, Fausto. O Desejo Amoroso em Os Canibais de Manoel de Oliveira. Porto: Mimesis, 2003.

CRUCHINHO, Fausto. The Woman in the Shop Window and the Man looking at Her: the Politics of the Look in Manoel de Oliveira's Ouvre. In: FERREIRA, Carolin Overhoff (Org.). On Manoel de Oliveira. Londres: Wallflower Press, 2008. p. 49-59.

FERREIRA, Carolin Overhoff. Os Descobrimentos do Paradoxo - a expansão europeia nos filmes de Manoel de Oliveira. In: JUNQUEIRA, Renata (Org.). Manoel de Oliveira: Uma Presença - Estudos de Literatura e Cinema. São Paulo: Perspectiva, 2010. p. 117-145.

JOHNSON, Randal. Aniki-Bobó. In: ELENA, Alberto (Org.). The Cinema of Spain and Portugal. Londres: Wallflower Press, 2004. p. 41-50.

JOHNSON, Randal. The Ethics of Representation. In: FERREIRA, Carolin Overhoff (Org.). On Manoel de Oliveira. Londres: Wallflower Press, 2008. p. 49-59.

MAIER-SCHOEN, Petra (Org.). Manoel de Oliveira. München: Filmzentrum, 2004.

MARTINS, Fernando Cabral. A Infância do Cinema. In: JUNQUEIRA, Renata (Org.). Manoel de Oliveira: Uma Presença - Estudos de Literatura e Cinema. São Paulo: Perspectiva, 2010. p. 3-12.

OLIVEIRA, Paulo Motta. De Amores, Cartas e Memórias - Camilo na lente prismática de Manoel de Oliveira. In: JUNQUEIRA, Renata (Org.). Manoel de Oliveira: Uma Presença - Estudos de Literatura e Cinema. São Paulo: Perspectiva, 2010. p. 51-66.

POMA, Paola. A Estrutura do Visível. In: JUNQUEIRA, Renata (Org.). Manoel de Oliveira: Uma Presença - Estudos de Literatura e Cinema. São Paulo: Perspectiva, 2010. p. 235-241.

ROVAI, Mauro Luis. Time and Memory: An Oblique Look at Journey to the Beginning of the World and A Talking Picture. In: FERREIRA, Carolin Overhoff (Org.). On Manoel de Oliveira. Londres: Wallflower Press, 2008. p. 122-141. 
SANTURBANO, Andrea. A Divina Tragédia ou o Olhar 'Tragirônico' sobre a Condição Humana. In: JUNQUEIRA, Renata (Org.). Manoel de Oliveira: Uma Presença - Estudos de Literatura e Cinema. São Paulo: Editora Perspectiva, 2010. p. 202-216.

\section{Resumo}

Este ensaio visa esclarecer como Manoel de Oliveira desenvolveu o seu método universalista, ou seja, a sua tendência de buscar no particular conclusões generalizantes sobre os dilemas da condição humana perante as alterações geopolíticas sofridas por Portugal, a Europa e o mundo ao longo dos últimos oitenta anos da sua atividade. Reconstroem-se, consequentemente, as relações entre a sua preocupação com a condição humana e o impacto dos cambiantes contextos nos quais tem filmado, desde 1931. Estas dimensões compreendem o local - sobretudo através da região do Porto e do Douro -, o nacional - em relação à identidade do seu país -, o supranacional - devido à adesão de Portugal à Comunidade Europeia, em 1986 -, o transnacional - devido à história portuguesa e às explorações marítimas, bem como o global - como resultado dos efeitos da globalização que Portugal sofreu a partir dos anos noventa.

\section{Abstract}

This essay analyses how Manoel de Oliveira has framed his universal method, that is, his tendency to look for generalising conclusions about the dilemma of the human condition within specific contexts during the eighty years of his filmmaking activity, by taking into consideration the geopolitical changes suffered by Portugal, Europe and the world. Accordingly, I will reconstruct the relationship between his interest in the human condition and the 
impact of the changing conditions in which he has produced films since 1931. The scales include the local mainly Porto and the Douro region -, the national - with regard to his countries' identity -, the supranational - given Portugal's history and the maritime explorations, as well as the global - as a result of globalisation's effects on Portugal from the 90s onwards. 